\title{
RETURN OF INEQUALITY IN MODERN SOCIETY? Test by dispersion of life-satisfaction across time and nations ${ }^{1}$
}

\author{
Ruut Veenhoven
}

Journal of Happiness Studies, 2005, vol.6, 457-487

\begin{abstract}
It is said that inequality is returning to modern nations and that this is manifest in the widening disparities in income in the late $20^{\text {th }}$ century. This trend is attributed to neoliberalism, globalisation and immigration, and is seen as a turn in the long-term trend towards a more civilised society.

In this paper I challenge the idea of rising inequality. I argue that income difference falls short as an indicator of inequality and cannot be meaningfully compared across time. Instead I propose to measure inequality in another way, not by difference in presumed chances for a good life, but by the dispersion of actual outcomes of life, using the standard deviation of life-satisfaction as an indicator.

Comparison across time in EU nations over the years 1973-2001 shows that the dispersion of life-satisfaction became smaller instead of larger. Comparison across 80 nations in the 1990s also shows lower dispersion in the most modern countries.

So the trend towards greater equality seems to persist. If there is any truth in the theory that access to scarce resources has become more unequal, the tendency must have been compensated in some way, possibly by greater equality in personal capabilities.
\end{abstract}

\section{INTRODUCTION}

\subsection{The issue: Return to greater inequality?}

Social inequality exists in all human societies, but some societies are more unequal than others. The degree of inequality in society is linked to the stage of societal evolution. Original hunter-gatherer societies were typically egalitarian, since accumulation of goods and power is hardly possible in its way of life. Harsh inequality was introduced in human society when our forefathers changed to a sedentary way of life where property of land and stocks became crucial. In these agrarian societies, warrior castes came to exploit the peasant population, slavery was introduced and women came to be discriminated (Sanderson 1995: 333-4). Inequality was particularly high in the advanced stage of agrarian society, where a $2 \%$ feudal elite consumed more than half of the gross national product (Nolan \& Lenski, 2004: 169). Inequities were much reduced in the change to industrial society during the last centuries. Inequality in income decreased much, though it may have increased in the first phase of industrialization $^{2}$. Inequalities in political power and social respect were also much abated, especially after the introduction of general suffrage and the development of welfare states (Nolan \& Lenski 2004: 271). Still inequalities in present day industrial societies are greater than they used to be in hunter-gatherer societies. The findings on this subject are schematized in figure 1.

This recent reduction of inequality in modern society is widely acknowledged and has been welcomed as 'the death of class' (Pakulski \& Waters 1996). The change is generally seen as the gradual fulfilment of the main promise of the French revolution (egalité). Progress optimists see it even as part of an ongoing evolution towards a more civilised society.

Yet recent developments challenge the prospect of continuous egalisation in advanced societies. Since the 1980 s there has been a growing concern about 'modern' inequality, both 
in the political arena and among social scientists. This modern inequality is denoted by words such as 'poverty' and 'social exclusion'. The trend is characterised by terms such as 'polarisation' and 'bi-partition' and is seen to give rise to a 'two-third society' in which a large minority is increasingly falling back. One issue in this discourse is the persistence of old inequalities in modern society, in particular the continuance of social class. A spokesman for this view is Marshall (1997). Another issue is the appearance of 'new' inequalities, such as between pensioners and young adults, and between settled citizens and new immigrants. Noll (1999) has crisply reviewed this literature.

Modern inequality is attributed to modern developments, in particular to neoliberalism and globalisation, which are seen to be to the advantage of a professional elite but to involve most people in a 'race to the bottom'. These forces will also strip the welfare state and therefore cause the downfall to be deeper. Immigration will also play a role, because migrants enter society from the bottom and are easy prey for exploitation (e.g. Sassen 1991, Wilterdink 1993). The growing complexity of society is also seen to widen the gap between high educated and low educated citizens.

All this suggests that we are facing a new rise of inequality. Harrisson \& Bluestone (1988) refer to this development as 'The Great U-Turn', meaning that the downward trend of inequality is reverting into an upward trend. This latter theory is depicted with the dotted line at the right in figure 1.

If inequality were indeed returning in modern society, it would be a severe blow to progress optimism. It would also be a testimonium paupertatis for social democracy. New inequality could further bring various harmful consequences in its trail, such as social turbulence and possibly revolutionary upheaval. For these reasons several politicians call for timely countermeasure, among which the conservation of the welfare state, and in line with this the European Union has proclaimed the combating of poverty and social exclusion to be a political priority (Lisbon declaration 2001).

Before swallowing the medicine one should check the diagnosis. Is inequality on the return? That is an empirical question. To answer it we need a good measure of social inequality, preferably a comprehensive measure that allows comparison over time and across nations. Unfortunately we lack such a measure as yet. Current empirical measures of inequality are pretty much tailored to the last century's situation and are not suited for charting long-term development.

\subsection{Current measures of inequality in nations}

Social inequality is typically conceived as difference in access to scarce resources. In sociological textbooks the most commonly mentioned scarce resources are 'income', 'power' and 'prestige'. These were central issues in the $20^{\text {th }}$ century emancipation movements of labourers and women and still shape the discourse on inequality today. In the practice of measurement the concept is narrowed even further.

\section{Focus on having}

Difference in ' access' to scarce resources is typically measured by being in 'command' of the said scarce resources. That is: not by the assets one could have, but by the assets one actually has. The reason is obviously pragmatic, it is difficult, if not impossible, to measure potential assets. Still, this practice defines people who do not care about money, power or prestige as 'deprived' and thereby equals difference in 'preference' with difference in 'chance'. People who opt for a modest lifestyle, such as hippies or early retirees, are classified as 'poor' and society is held responsible for their condition. Yet the more lifestyles diverge, the less is this practice defensible. 


\section{Restriction to income}

Difference in 'command of resources' is typically measured by difference in 'income'. The reason is again pragmatic. It is difficult to quantify differences in power and prestige, and certainly to follow change in these matters over time.

Though income is the best measurable resource, comparison of income inequality over time is beset with methodological problems ${ }^{3}$. As a result there is quite some divergence in estimates of the trend in income inequality. The most sophisticated studies suggest that income inequality rose in some nations at the end of the $20^{\text {th }}$ century, particularly in the UK and the USA. Yet this did not happen in all western nations, for instance, income inequality seems to have remained stable in West Germany and to have decreased in Ireland, France and Finland (Alderson \& Nielsen 2002, Ritakallio 2001).

\section{Weaknesses}

Even if income inequality had risen in all modern nations, it would not have marked a wider return of social inequality. Income was not such a scarce resource at the end of the $20^{\text {th }}$ century as it was at the beginning. Incomes tripled in this era. As a result, 'relative' poverty was less often found in conjunction with 'absolute' poverty. The new 'poor' in affluent nations do not face starvation. At the top of the income distribution one can see signs of diminishing returns. Though the rich tend to be happier than the poor, that difference is smaller in poor nations than in rich ones. In an affluent society such as the Netherlands income differences explain only some 3\% of the variation in happiness (Veenhoven 1997) and the causal effect of income on happiness is probably less ${ }^{4}$.

At a more basic level one can question the concept of 'differential access to scarce resources' as such.

Firstly, there is a problem with the notion of 'scarcity'. Something is 'scarce' if many want it but few can have, e.g. the best seats in a theatre or the biggest house in town. In this sense inequality is inevitable, since the supply of 'best' things is limited and the demand for it endless. Yet not everything wanted is really needed. We can also live with a place in the third row of the theatre and in an average house. Hence social policy typically aims at providing everybody with the necessities of life rather than trying to fulfil ever rising aspirations. Seen in that light, we should not bother about all inequalities, but only about inequalities that really hurt.

Secondly there is a problem in the focus on 'resources'. Though it is obvious that we need resources to gratify our needs, it is not so obvious what resources are most critical for this purpose. Are income, power and prestige really the key resources? One can think of resources that link up more evidently with human needs, such as 'love' (required for one of Maslow's mayor deficiency needs) and 'challenge' (required for growth needs). The resources measured in inequality research are in fact things that investigators assume to be necessary for a good life. Though such assumptions may have been realistic in historic conditions of austerity, they could be less applicable today.

This brings me to the wider point that it not so clear how much we need of the resources assumed to be essential for a good life. More is not always better, since resources are typically subject to the law of diminishing returns. This is even true for meta-resources such as income; the richer we get, the less additional income adds to our happiness (Veenhoven \& Timmermans 1998). Still another point is that it is typically not separate resources that matter, but the total resource mix. This leads into difficult questions about minimum requirements and synergetic effects. Restricting measurement to command of money does not solve that problem, since money cannot buy everything. 
These theoretical doubts are supported by recent empirical evidence. Income inequality in nations appears almost unrelated to final quality of life as measured by average happiness and health (Veenhoven 1996: 34) ${ }^{5}$. Apparently, income difference does not really hurt in present day affluent societies ${ }^{6}$.

Given these weaknesses of the current measure of social inequality, it is worth considering alternative methods. In this paper I propose a radically different approach, based on insights from the field of quality-of-life research.

\subsection{An alternative measure of social inequality}

Above we have seen that the current approach measures inequality by determining differences in access to scarce resources, in other words, as difference in life-chances. An alternative is to measure social inequality by dispersion of life-results. Following this, I propose to measure inequality in nations by the dispersion of life-satisfaction. Below I expand on that approach and enumerate its advantages.

\subsubsection{Distinction between life-chances and life-results}

Life-chances are preconditions for a good life; life-results mark a good life itself. Both chances and results can be either 'external' or 'internal'. Together these distinctions produce the four 'qualities of life' presented in figure 2.

External life-chances are those environmental conditions required for a good life. Biologists refer to these conditions as the 'biotope'. This consists of the physical conditions required for life, such as suitable air and availability of food, and more importantly, for social animals it also involves the 'sociotope' they form with congeners. In the case of humans that is society. I denote the quality of the whole of external life-chances with the word 'livability'.

Internal life-chances are the individual's capabilities to exploit these environmental chances. Biologists call this 'fitness', since the required capabilities depend on environmental demands. Internal chances involve typically appropriate physical and mental functioning; they also involve responsive development of capabilities, such as intelligence. I refer to this all as 'life-ability'. I will come back to this matter in the discussion section.

External life-results are the environmental effects of a life. In biological thinking this is an organism's functionality in the ecological system, in sociological thinking it is a person's contribution to society. I refer to the whole of these effects as the 'utility' of life. Although I do not use this concept in this paper, the above is to clarify the difference with 'internal' liferesults'.

Internal life-results are the outcomes of life for an individual. Biologists emphasise 'survival' in this context. Alongside mere continuation of life one can also consider enjoyment of it. Mobile organisms can feel good or bad, probably because this is required for finding a livable biotope. The development of cognition in humans has not annulled this affective signal system, it has just enabled us to estimate and articulate average affect and on that basis judge the quality of our life as a whole. Hence in the case of humans the internal results of life also manifest in life-satisfaction. This provides a basis for measuring inequality in life-results. 


\subsubsection{Focus on disparity in life-results}

I have discussed these concepts in more detail elsewhere (Veenhoven 2000). In that paper I also considered their measurability, in particular the possibility of comprehensive measurement. I argued that current sum-scores add apples and oranges and fail to acknowledge that external requirements depend on internal abilities (pp. 26-29). I concluded that only internal results of life can be measured comprehensively because the total reflects in how long and happy people live (pp. 31-33). On that basis, I reasoned that the livability of a society can only be measured indirectly by the final quality of life of its citizens as expressed in degree and duration of life-satisfaction (pp. 33, see also Veenhoven 1996). In this paper I extend this view to the measurement of social inequality. Social inequality is measured indirectly using the dispersion life-satisfaction.

\subsubsection{Restriction to disparity in life-satisfaction}

The first attempt to measure social inequality using dispersion in life-results considered variation in years lived among members of society. LeGrand (1987) estimated dispersion in age at death in 32 countries around 1980. He quantified these differences in Gini-coefficients and in an Atkinson Index. Together with Joop Ehrhardt I did a similar analysis for 29 nations in the 1980's (Veenhoven 1993: 132-4). One problem with this method is that it applies only for generations that have already died. Hence it informs us about inequality in the past. Another problem is that data fall short. Life-tables are only available for a limited number of countries and these data often do not allow comparison across time. Hence I decided to drop this indicator for the time being ${ }^{7}$.

An alternative is to measure inequality by dispersion in life-satisfaction. To do this one can use surveys and consider dispersion in responses to questions about enjoyment of life. This method does provide timely data. I have explored this approach in several earlier papers (Veenhoven 1990, 1992). Initially the data were too limited to be conclusive, but meanwhile more and better data have become available, and this now allows comparison across time and nations. I make use that opportunity in this paper.

\subsection{Measurement by standard deviation of life-satisfaction}

Life-satisfaction can be measured by simply asking people how they feel about their life as a whole. This is common practice in quality-of-life surveys. Inequality of life-satisfaction in a nation manifests in the distribution of responses in a general population sample and can be quantified using statistics of dispersion. The standard deviation appears to be one of the most suitable statistics for this purpose (Kalmijn and Veenhoven 2005). Accordingly, I propose to measure social inequality in nations using the standard deviation of life-satisfaction.

\subsubsection{Doubts about life-satisfaction}

The study of life-satisfaction has developed considerably over the last decade (Diener 1999, Veenhoven 1997), but there are still many qualms about measurability, comparability and the significance of the matter. Many of these misgivings can also be raised when applying this concept to inequality.

\section{Measurability}

With respect to measurability, it has been maintained that self-reports of life-satisfaction do not reflect well how people actually feel about their life. One argument is that people do not really know their true feelings, another that they do not report what they feel honestly. It has also been argued that life-satisfaction cannot be compared interpersonally. Objections of this kind have instigated a lot of empirical validation research, which so far has refuted these qualms. (E.g. Saris \& Scherpenzeel 1996, Veenhoven 1997, 1998). It appears that almost all 
adults have an idea about how they feel about life and that they report this fairly honestly in anonymous interviews. The predictive power of life-satisfaction self-ratings implies that the experiential range does not differ too much. In an adaptive perspective it is also rather unlikely that the range of experience differs very much among congeners.

\section{Comparability}

It has also been claimed that life-satisfaction cannot be compared across cultures.

A main theoretical argument is that standards of the good life are culture specific. An assumption behind this objection is that life-satisfaction is 'calculated' cognitively by comparing life-as-it-is with collective notions of how-life-should-be; life-satisfaction is in fact equated with contentment. That assumption fits nicely with psychological cognitivism and sociological constructionism, but it does not match the evolutionary view. I have already placed life-satisfaction in this perspective (see above), arguing that adaptation of higher organisms is guided by affective signals and that humans are conscious of how they feel and can estimate and articulate their average mood. There is good evidence that appraisals of lifesatisfaction draw on this affective information in the first place (Veenhoven 1991, 1997, and 2000), and since mood is a universal intuitive experience, so must be life-satisfaction.

Next, a methodical argument holds that cross-cultural comparabily is thwarted by systematic differences in measurement bias. It is claimed that Americans overstate their happiness while the Japanese tend to understatement. As yet there is no direct evidence for such distortions and the high explanatory power ${ }^{8}$ of average life-satisfaction in nations makes it unlikely that it bears much significance. Moreover, these misgivings concern the comparability of average level of life-satisfaction in nations, while the focus is here on differences in life-satisfaction in nations. Even if the level of life-satisfaction is overstated in some nations, the difference within can still be comparable.

The question is rather whether there are cultural factors that differentially effect the dispersion of responses across nations. One such factor could be the tendency to present oneself as average and prefer the middle category of response scales. This tendency has been attributed to the Japanese (Iijima 1981), but that view is not supported by the data. Another distortion could be in cultural differences in aptness to exaggerate. Preference for extreme answers will inflate standard deviations of life-satisfaction. This source of bias could be a problem in comparisons across nations ${ }^{9}$ but is unlikely to affect comparison through time within nations.

\section{Significance}

A related objection holds that life-satisfaction bears no significance. If life-satisfaction depends on the gap between standards and reality, one can get satisfaction by lowering standards. Life-satisfaction is thus put to one side with resignation. In a similar vein it is argued that life-satisfaction is an evanescent thing, because standards tend to adapt to reality. This is seen to imply that life-satisfaction reacts only to short term ups and downs and that it is insensitive to long term quality-of-life. All this boils down to the thesis that life-satisfaction is 'relative' and therefore lacks any absolute value.

Again qualms are based on the assumption that life-satisfaction results from cognitive evaluation that anchors in social construction rather than in human nature. Life-satisfaction is seen to result from perceived realisation of wants. Above I have argued rather that lifesatisfaction reflects gratification of needs, since nature has safeguarded the meeting of essential conditions by linking it to hedonic affect. That is why we cannot feel well without companionship and some challenge in the long term, but can easily adapt to a life without colour-TV. Though it is difficult to prove that life-satisfaction draws on the gratification of needs, it can be proved that it does not depend on realisation of wants. Elsewhere I have 
falsified several implications of this theory (Veenhoven 1991) and as yet I have not seen good counter evidence.

A problem in this discussion is that the objections do apply to several domain satisfactions. In his famous study among American soldiers, Stouffer (1949) showed that career-satisfaction depends on social comparison, a phenomenon that came to be known as 'relative deprivation'. In the case of income-satisfaction there is also experimental evidence for 'reference shifts' (e.g. VanPraag1989). These findings are wrongly generalised to all satisfactions. Yet the informational basis differs across objects of satisfaction. Other domain satisfactions draw much more on internal information, for instance satisfaction with marriage and satisfaction with health. In an evolutionary perspective it is likely that satisfaction with the most vital domains of life draw least on social comparison. In that context it is the more understandable that life-satisfaction draws on hedonic level of affect rather than on social comparison. Not only is this an evident and compelling source of information but also there is no good alternative for appraising life-as-a-whole. Income can be easily compared with the Jones' but overall quality of life is difficult to determine in compare.

\subsubsection{Suitability of life-satisfaction in this context}

After refuting all these qualms about life-satisfaction it is good to bring its strong points back to mind. My goal in this paper is to test the theory that inequality is on the rise in modern society and for this purpose I need an indicator of inequality that meets three demands. In the first place the measure should reflect difference in 'relevant' resources, there is no point in measuring inequality in access to pettiness. Secondly the measure chosen should comprehensively capture all these inequalities; restriction to inequality in particular resources can seriously distort the picture. Thirdly, the measure should be comparable across time and nations, which is required for testing the claim that inequality is returning in modern society. How well are these demands met when we measure social inequality by dispersion of lifesatisfaction?

Above I have argued that life-satisfaction depends on the gratification of needs, rather than on the perceived realisation of wants. Thereby this indicator meets the demand of 'relevance'. Life-satisfaction is enjoyment of one's life-as-a-whole and I have argued that lifesatisfaction is one of the most encompassing indicators of quality-of-life available. So, this indicator also meets the requirement of comprehensiveness. Lastly we have seen that lifesatisfaction is well measurable within and across nations. Hence life-satisfaction also meets the comparability requirement.

So, all these demands are met by the proposed method of measuring inequality using the standard deviation of life-satisfaction. Moreover, this indicator has the beauty of simplicity.

\subsubsection{Availability of data}

Life-satisfaction is a current item in welfare surveys, so there is a lot of data on dispersion of life-satisfaction in nations. These data are readily available in the World Database of Happiness ${ }^{10}$, which presents observed means and standard deviations of life-satisfaction for all general population studies ever held (Veenhoven 2002). There are now data about all the rich nations and the former communist countries, but the data for third World nations are still incomplete. Time-series data are available for the USA since 1945, for Japan since 1958 and for the EU-nations since 1973. This suffices to test the hypothesis under investigation.

\subsection{Research questions}

Now we have a new measure of inequality in nations, we can go on to specify how this indicator can be used to test the theory of growing inequality in modern society. 
A preliminary test is to check whether the distribution of life-satisfaction tends to a bimodal pattern. This is implied in notions of an emerging 'split' in society. Frequency distributions can be visually inspected for such a pattern.

The main test is to inspect whether standard deviations did increase over time. This can be checked by a correlational analysis in which size of the standard deviation is crossed with the year of observation. This test will be elaborated by partialling out a possible confounding factor, that is, increase in the level of happiness.

Lastly, the wider theory of modern inequality can also be tested by comparing dispersion of life-satisfaction across nations, and in particular by comparing standard deviations in more and less advanced countries. If the theory of the U-curved time trend holds truth, we can expect greater inequality in the most advanced nations in the 1990s.

\section{DATA}

The analysis is based on two data-sources, the Eurobarometer surveys over the years 19732001 and the World Value Surveys in the 1990s.

\section{Eurobarometer}

The Eurobarometer survey is held twice a year in all EU member states and involves representative samples of the population aged 15 years and older. The regular sample size is about 1000 in each country. This survey program started in 1973 in the nine member states of that time: Belgium, Britain, Denmark, France, Ireland, Italy, Luxembourg, The Netherlands and West Germany. Greece joined in 1980, Portugal and Spain in 1985. The surveys have also been held in Austria, East Germany and Sweden since1990.

All surveys involved a question about life-satisfaction, which reads as follows:

'On the whole, how satisfied are you with the life you lead?'

- very satisfied

- fairly satisfied

- not very satisfied

- not at all satisfied

The responses to the question are then given numerical values; 'very satisfied' is denoted as 4 and 'not at all satisfied' as 1 . On that four-step scale, the standard deviation can maximally be 1,5 (if $50 \%$ scores ' 4 ' and the other $50 \%$ ' 1 ') and minimally zero ( $100 \%$ of the responses in one response category).

The life-satisfaction item was in the core-module from the beginning. In the years 1997, 1998 and 1999 life-satisfaction was assessed only once. Since the aim is to compare over a time I did not include the countries that joined in 1990 or later. This leaves us with 12 cases, 9 nations with a time-series of 23 years, one with a time-series of 16 years and two with a time-series of 11 years. Given some missing cases, the total number of data points is 447 .

World Value Survey

The World Value Survey started as an extension of the European Value Study. The first wave took place in the early 1980s and involved 28 nations. The second and third waves were held in the 1990s and involve altogether 53 nations. The fourth wave was completed in the years 1999 to 2001 and covered 60 nations. Together this provides us 81 nations in the 1990s. 
Alongside questions about happiness and mood, the questionnaire also includes a single item on life-satisfaction. This question reads as follows.

'All things considered, how satisfied are you with your life as a whole now?'

$\begin{array}{cccccccccc}10 & 9 & 8 & 7 & 6 & 5 & 4 & 3 & 2 & 1 \\ \text { satisfied } & & & & & & & & & \text { dissatisfied }\end{array}$

This 10-step numerical response scale provides a better view on the dispersion of responses than the 4-step verbal scale of the Eurobarometer.

Data were sourced from Inglehart (2004). An overview of the standard deviations per country is available on the World Database of Happiness (Veenhoven 2004).

\section{$3 \quad$ RESULTS}

\subsection{No bi-modal distributions}

In theory the distribution of responses could take five different shapes. These possible distributions are presented in figure 3. In present day nations, most observed distributions are of the same type, the negatively ${ }^{11}$ skewed uni-modal distribution. The distribution of responses to the 10-step life-satisfaction question in Western Europe is presented in figure 4 as an example. Normal distributions appeared in some developing nations such as Bangladesh. Positively skewed distributions are observed in post-communist countries such as Armenia and in African nations such as Zimbabwe.

In none of the 80 countries in the World Value Survey did we find a bi-modal distribution of life-satisfaction, nor did we observe any tendency towards such a pattern over time in the Eurobarometer surveys. In this light talk about 'split-society' appears to be mere rhetoric.

\subsection{Standard-deviations diminished over time}

Growing inequality is more likely to manifest in a flattening of the distribution, which will (also) manifest in a rise in standard deviations. This possibility was checked on the Eurobarometer data, which allow a comparison over 28 years (1973-2001).

As a first check, standard deviations were plotted against time for each nation separately. These plots are presented in appendix 1. For reasons of surveyability the figures present the average standard deviation in each year (mean of observed SD in spring and fall survey ${ }^{12}$ ). Visual inspection shows a decline in most cases. Standard deviations declined in ten of the thirteen nations, and in six of these the decline was statistically significant $(\mathrm{p}<.05)$. Standard deviations got slightly higher in three countries (France, East Germany and Ireland) but none of these ascents were significant ${ }^{13}$.

In order to visualise the general pattern; the data are also presented in a joint plot. For this purpose the standard deviations of the different nations per year are combined in an average that is weighted by population size. The combination in an average is required to see the time-trend, which otherwise gets lost in the variation across nations. Weighting by population size is required to prevent distortion due to little countries such as Luxembourg.

The result is presented on figure 5, where we can see a clear pattern of declining standard deviations, in other words, a growing equality in life-satisfaction. The unstandardized 
regression coefficient is -.00176 , which means a yearly drop of inequality by $0,18 \%$. The $95 \%$ confidence interval around that value ranges from -.001 to -.003. Since the value zero is not in that range, we can take it as read that inequality did decrease in Western Europe over these years. The decease is quite small however, if this trend continues linearly, it will take about 50 years to reduce the standard deviation on this 4-step scale from its current level of 0.7 to 0.6 . Another 300 years would be required to reduce the standard deviation to zero. However, longterm development usually goes in small steps.

\section{More so in Southern Europe}

Figure 5 does not include the three Mediterranean nations that entered the EU later: Greece, Portugal, and Spain. I also considered these cases separately. Since they are all SouthEuropean nations, I added the other South-European nation to this cluster, that is, Italy. As a contrast group I selected four typical North European nations (Britain, Denmark, West Germany and The Netherlands). For all of latter we have data since 1973.

The data are presented in figure 6a and 6b. In these figures the fat trend-line in the middle represents the mean level of life-satisfaction and the thin lines the variation around that mean. In figure 6a we can see that the level raised somewhat in the North-European nations between 1973 and 1996, and that the dispersion of life-satisfaction became slightly smaller. The homogenisation around the mean is hardly visible however. In figure $6 \mathrm{~b}$ we see a similar pattern in South-Europe over the years 1985-1996, both the rise of average level of life-satisfaction and the reduction in spread are better visible. Note that the level of lifesatisfaction is substantially lower in the South-European countries.

\section{Reduction dispersion not wholly attributable to rising average}

We have seen that the distribution of responses on the 10-step scale is quite skewed in figure 4 . Further rises in the level of life-satisfaction will produce an even greater concentration in these response categories. As a result, standard deviations will be lower. The 4-step response scale used in the figures 5 and 6 could enhance this effect, because it provides only two gradations at the positive side ${ }^{14}$

A partial correlation analysis was performed to estimate the pure trend of dispersion. Dispersion of life-satisfaction was correlated with year, while controlling for average level of life-satisfaction. Since all the nations are included, the analysis is limited to the years 19852001. The results are presented in figure 7 . The zero-order correlation confirms that dispersion of life-satisfaction is linked to level of life-satisfaction ( $r=-.75)$, and that the level has risen over these years $(r=+.56)$. Yet we also see that the decline of dispersion was even stronger $(r=-.75)$ and that statistical control of the rising level reduces the trend only marginally $\left(r_{p}=-.46\right)$. Similar results were obtained when this analysis was performed on different sets of nations and for different periods.

\section{Similar trend in Japan and USA}

A look at the World Database of Happiness (Veenhoven 2005) reveals that standard deviations of life-satisfaction have also diminished in Japan and in the USA. So this is not just a local European pattern, but also a wider concomitant of modernisation.

\subsection{Dispersion lowest in most modern nations}

Next to the above comparison through time, I also compared across nations. Since the theory of modern inequality sees growing differences in society as a result of societal evolution, it would predict greater dispersion of life-satisfaction in the most advanced nations. 
For a first global check, look back at figure 6. By all standards, the North-European nations in figure 6a are more advanced than the South-European nations in figure 6b. Yet in 1985 the dispersion of life-satisfaction was somewhat smaller in the former nations (SD = 0,67 ) than in the latter (SD $=0,71$ ), which is contrary to the hypothesis. In 1996 the dispersion was about the same in North and South Europe, which also does not fit the theory, particularly not since the South-European nations had gone through a modernisation spurt. The only piece of support for the prediction is in the linear extrapolation of the trend to the future, which suggests that Southern dispersion will soon dip under northern dispersion.

A limitation of this comparison is that it is about only eight countries and that the difference in social development between these nations is not too great. We get a better view on the link between modernity and inequality if we consider a larger and more varied set of nations. For this purpose I analysed the data from the World Values Survey. Standard deviations on 10-step life-satisfaction were plotted against several indicators of modernity of nations.

Correlational analysis shows that dispersion of life-satisfaction is negatively related to all indicators of modernity. There is a very strong negative correlation with economic development ${ }^{15}(\mathrm{r}=-.68)$. Likewise dispersion of life-satisfaction correlates negatively with freedom in private life ${ }^{16}(-.59)$, informatisation ${ }^{17}(-.45)$, urbanisation $^{18}(-.30)$ education ${ }^{19}$, (-. $48)$ and tolerance (-.46). These latter correlations are much abated when economic development is controlled, but the statistical relations with freedom and informatisation remain significant ( $\mathrm{r}_{\mathrm{p}}=-.35$ and -.32 respectively). Together these variables explain $77 \%$ of the differences in dispersion of life-satisfaction.

The scattergram of dispersion in life-satisfaction by economic affluence is presented in figure 8. This scattergram does not reveal a $U$ shaped pattern. The relationship is quite linear, dispersion of life-satisfaction being smallest in the most modern nations. Inspection of the other scattergrams also does not reveal any such U-curve. So the theory of theory of 'The Great U-turn' appears to be wrong. What we see is the reverse.

Interestingly, the correlation between dispersion of life-satisfaction and income-inequality ${ }^{20}$ is not too strong: $r=+.30$. This supports my contention that income differences capture only a part of the variation in access to relevant resources in present day society. Ott (2005) discusses this matter in more detail in this issue.

\section{DISCUSSION}

The purpose of this paper was to check the notion that social inequality is on the return in modern society. The data used here clearly contradict that idea and in fact show the converse, disparities in life-satisfaction have become smaller instead of larger. In this respect, modernisation still goes hand in hand with egalisation.

\subsection{Compatibility with evidence of modern deprivation}

Still, the idea of growing inequality in modern society must come from somewhere, and there are indeed indications of widening gaps in some life-chances. In some countries at least, incomes increased less at the bottom of the income distribution than at the top and there are also reports about widening class differences in educational achievement. More important, there are also signs of growing disparities in outcomes of life. In West Germany, the poor became less happy between 1988 and 1998, both absolutely and relatively (Bulmahn 2000: 423). Likewise some investigators have observed growing class difference in health and life expectancy (Kunst et. al. 2001). How can this be reconciled with the observed egalitarisation of life-satisfaction? 


\section{Fit with disparities in chances}

One answer has already been mentioned in the introduction to this paper. Not all differences hurt. Only differences in access to relevant resources will materialise in dispersion of lifesatisfaction. So, the newly emerged disparities are probably not essential for need gratification. Since these disparities mostly concern money matters, this is quite probable. Income differences hardly matter in affluent society. Though most people would like more money, they do not really need it. Hence relative income hardly affects happiness in rich nations (Veenhoven 1999, Schyns 2001).

The other answer is that people may have become more able in dealing with the problems of life. Below I will discuss that hypothesis in more detail. If this is true, this may have compensated possible declines in distributional justice in some fields.

\section{Fit with difference in outcomes}

The reports of widening disparities in life-results are more problematic at first sight. Still there are several possible explanations.

A methodical explanation could be that these reports reflect mere blips in hectic development rather than the main trend. We can see in the trend plots for separate countries (Veenhoven 2005) that there is also lot of variation in standard deviations of life-satisfaction and that differences have widened temporarily in some cases. Since inequality is a hot issue, this can give rise to selective reporting.

A substantive explanation could be that people become ever more satisfied in modern society (which reduces the standard deviation), but that the dwindling number of dissatisfied are concentrated at the bottom of the social ladder. This could be due to the fact that social mobility has become more dependent on psychological characteristics that are closely linked to life-satisfaction, such as assertiveness, energy and self-control. Yet this explanation implies that the correlation between life-satisfaction and social prestige must have grown over time, yet such a development is not visible in the available data (World Database of Happiness, Catalog of Correlates, Subject code S 9). So, if this effect exists at all, it must be small in size or number.

\subsection{Possible explanations}

This leaves us with the question why inequality has decreased during the last decade. Proving causality borders on impossible in this trade, but I can suggest two lines of explanation.

For this purpose I invite the reader to recall the fourfold classification of qualities of life, presented in the introductory section. This scheme helps to see that the observed reduction in dispersion of life-satisfaction can be explained by two kinds of life-chances: external and internal chances. If we depart from external chances, we can explain the egalitarisation of life-results by greater equality in access to scarce resources, which fits current thinking. If we consider internal chances, the equalisation of life-results must be attributed to more equal life-abilities. To my knowledge this is a somewhat rare perspective.

\section{More equal access?}

As noted in the introduction of this paper it is commonly believed that inequality in access to scarce resources has widened over the last decade, in particular access to a good income. Now that we have seen that dispersion in life-satisfaction has diminished, we must consider the reverse, that is, that differences in access have decreased, at least differences in access to relevant resources. This is not unlikely if one considers the following developments. 
Firstly, modernisation has created a more livable environment for most people. Some may doubt this fact when reading the newspaper, but it is a matter of fact is that we live longer and happier than ever (Veenhoven 2005b). This rise in access to relevant resources for everybody has diminished the difference in access to these.

Secondly, modernisation involves individualisation and life-style differentiation and may thus have created a greater diversity of opportunity structures. This may have reduced scarcity of resources and it may also have produced a better fit of societal supply to the citizens' needs.

Further it is evident that many traditional inequalities have lessened, the social ladder has shortened; status differences have become less pervasive and as a consequence respect has become a less scarce commodity. This reflects in the rising self esteem in modern society. Several minorities have successfully pressed for equal opportunities during the last decades, in particular women, handicapped people, homosexuals, black people and the elderly. The politics of empowerment seem to have worked and still to be working for the new migrants.

This is not to deny that modernisation has also created 'new inequalities' but apparently these developments have been counter balanced in some way.

\section{More equal life-ability?}

Commonly 'access to resources' is seen in terms of rights and opportunities linked to social positions. Access is then a matter of distributional justice, which depends on the structure of society. Yet access depends also on personal capabilities, such as understanding and perseverance. Personal wisdom is especially crucial where access to 'relevant' resources is concerned, because this requires insight into what one really needs. Seen in this light, the reduction in dispersion of life-satisfaction can also be explained by a growing ability to deal with the problems of life. The more able people are, the more of them will succeed in gratifying their needs and hence become more satisfied with their life.

Why might life-ability have increased in Western Europe over the last decade? Again several possibilities come to mind. One possibility is that opportunities for personality development have improved, pedagogy has begun to focus more on autonomy, formal education has been extended and the period of youth has been lengthened, providing more opportunity for experimentation. Another possible reason is the progress made in treatment of mental problems. Both psychotherapy and the psycho-pharmacy have improved considerably, and this may be responsible for the substantial reduction in the percentage 'very dissatisfied' found in the general population.

Treatment for unhappiness is often denounced as 'mind control'. The easy rebuttal of this argument is that the observed egalitarisation of life-satisfaction cannot be fully explained in this way, e.g. because only a part of the dissatisfied are depressive. A more basic retort is that the greater availability of treatment is a typical case of more equal access to relevant resources. Why sniff at general access to anti-depressants while bemoaning inequalities in access to heart-surgery?

\section{CONCLUSION}

Social inequality in nations can be measured by the dispersion of life-satisfaction. Application of this indicator reveals that inequality is declining in modern society. Comparison over time in the EU nations over the years 1973-2001 shows that the standard deviation of lifesatisfaction has gradually decreased. Comparison across 53 of the world's nations in the 1990s also shows that standard deviations are systematically smaller in the most modern nations. This means that the long-term trend toward lessening inequality is still actively ongoing 


\section{Figure 1}

Long-term development of social inequality

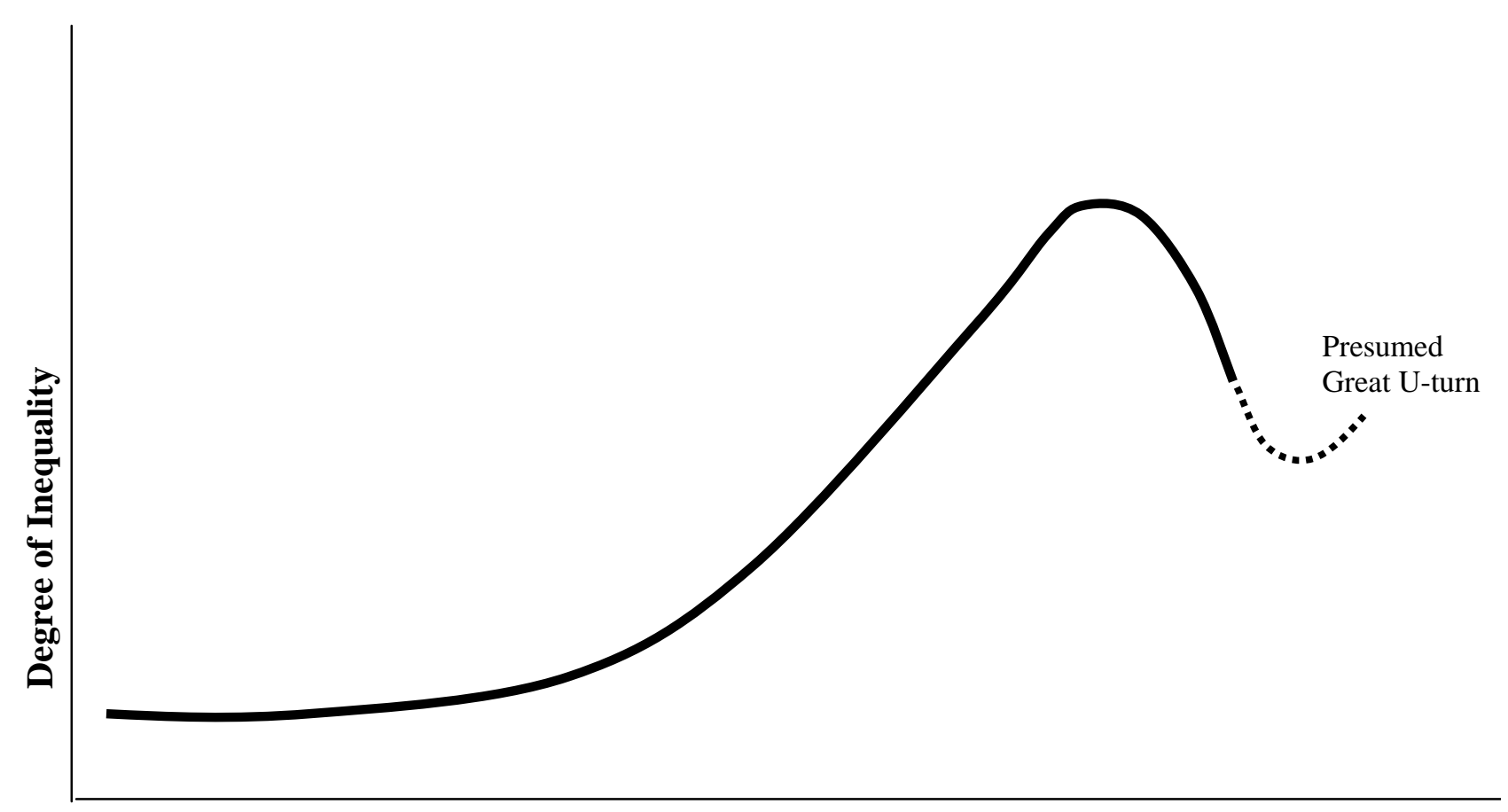

Type of society

Hunter-gatherer

agrarian

industrial

Based on Nolan \& Lenski (2004) 
Figure 2

Four qualities of life

\begin{tabular}{|l|c|c|}
\hline & External & Internal \\
\hline Life-chances & Livability & Life-ability \\
\hline Life-results & Utility of life & Satisfaction with life \\
\hline
\end{tabular}

Source: Veenhoven 2000 


\section{Figure 3}

\section{Possible patterns of dispersion}

Possible frequency distributions

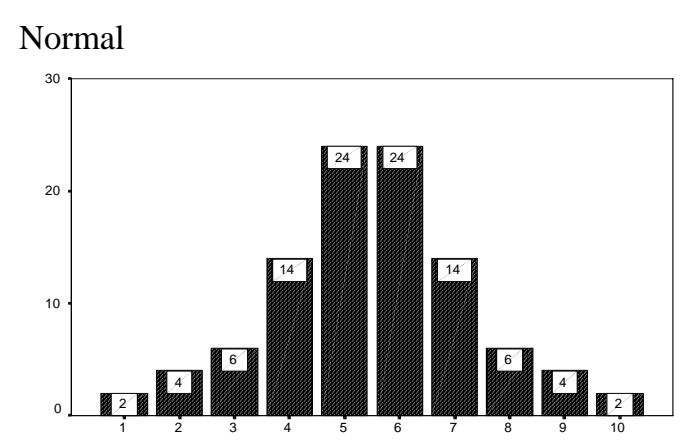

Bi-modal
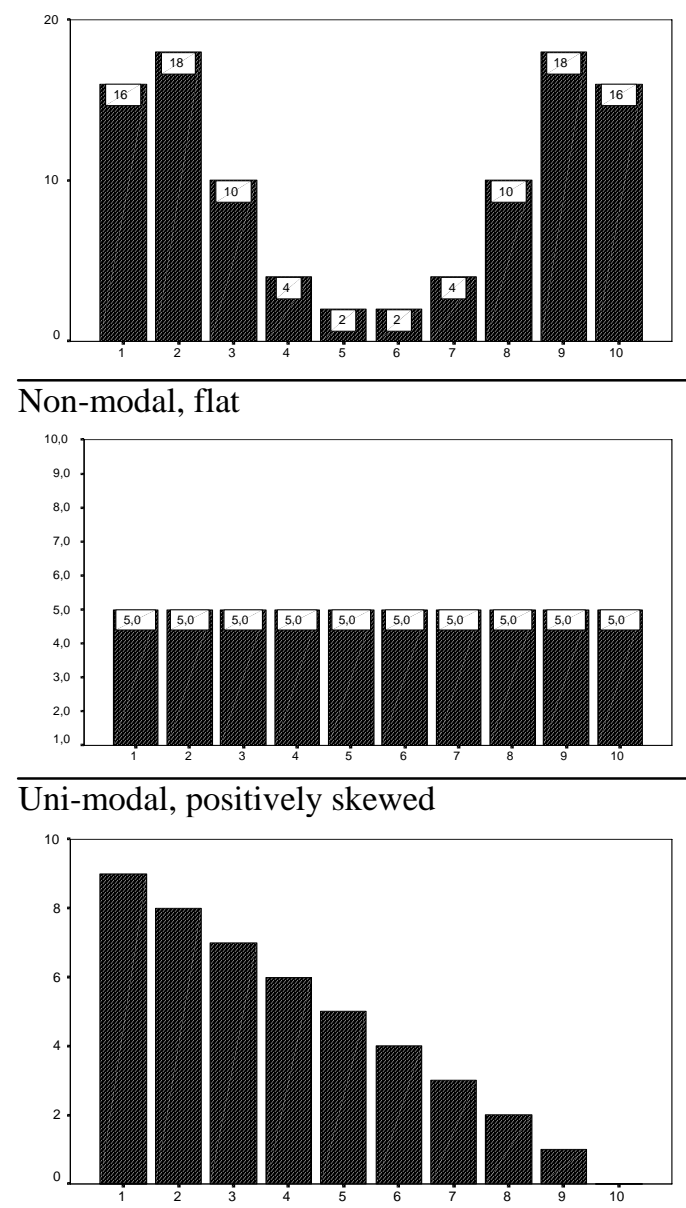

Uni-modal negatively skewed

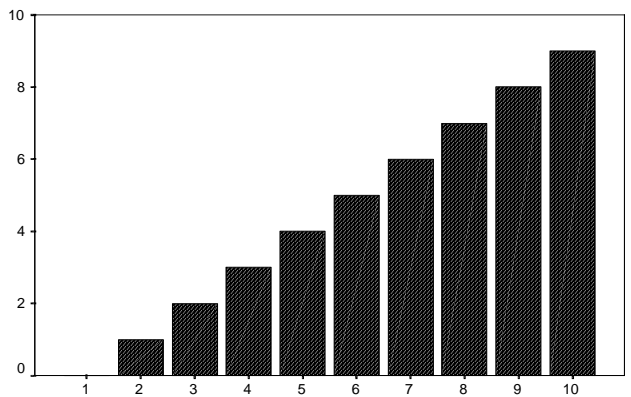

Mean Standard Deviation

$5,5 \quad 1,81$


Figure 4.

Actual distribution of life-satisfaction in modern Western Europe.

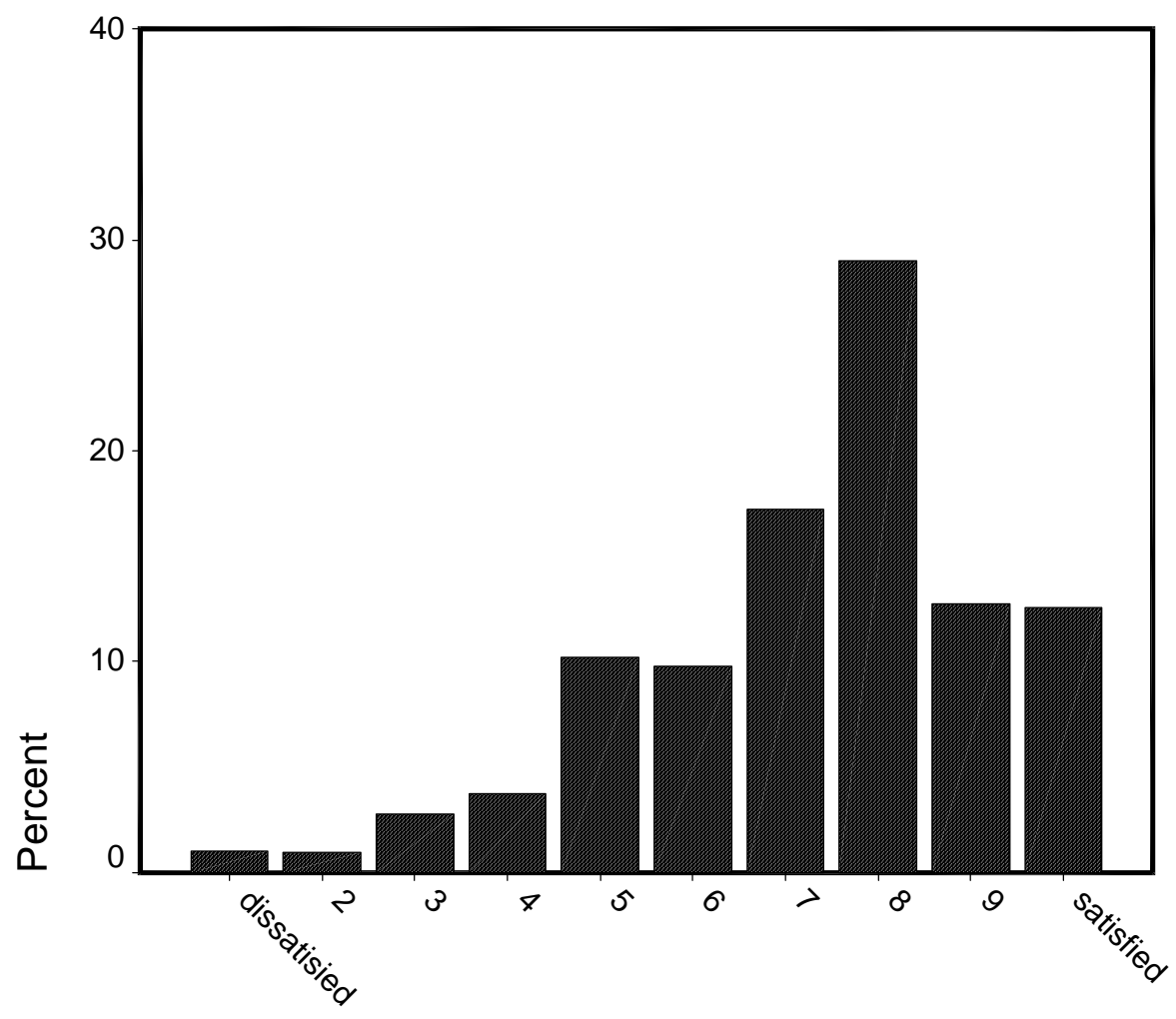




\section{Figure 5}

Trend in dispersion of life satisfaction in the European Union

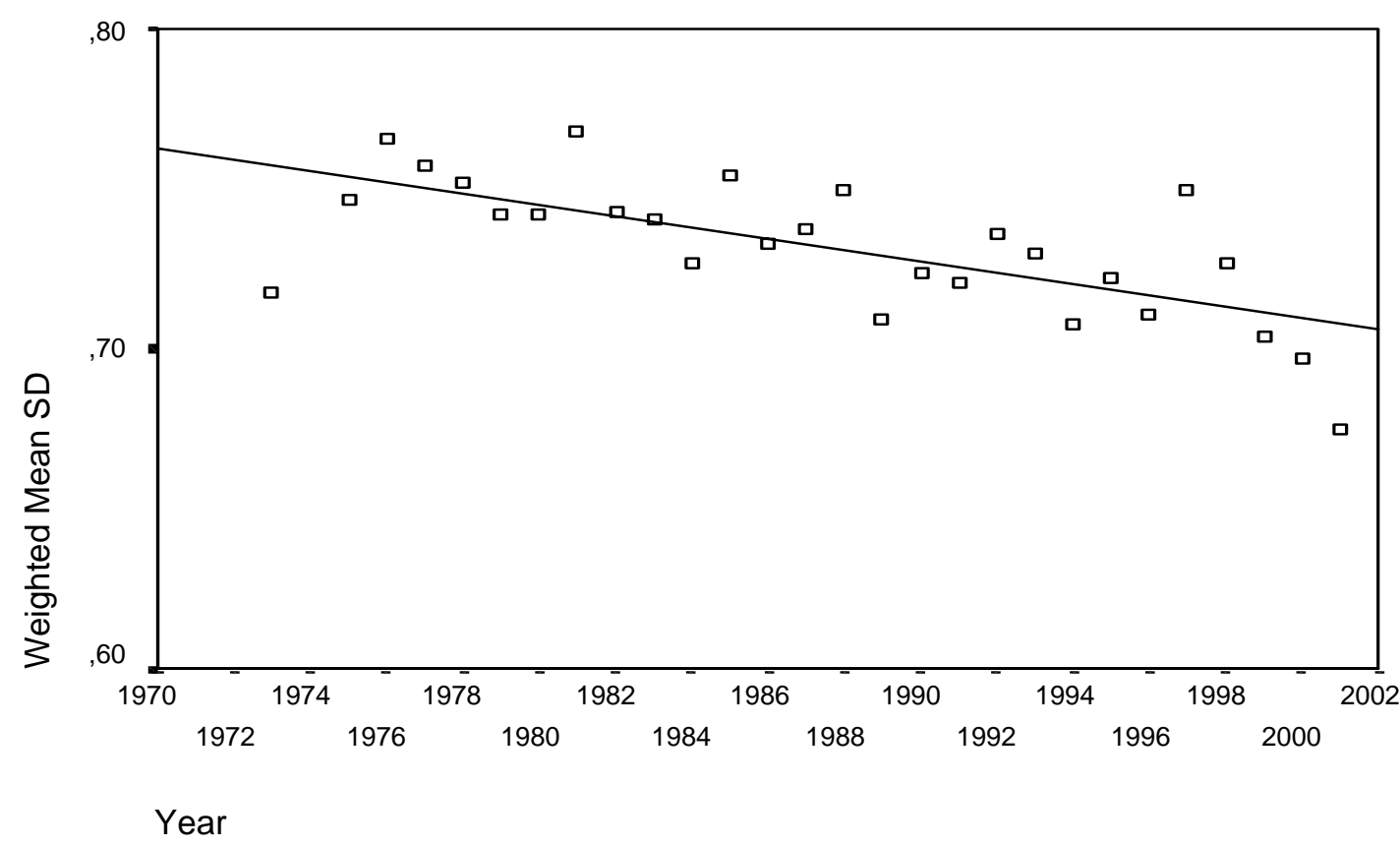




\section{Figure 6}

Trend in life-satisfaction in Northern and Southern EU nations separately

4 North-European Countries 1973-2001

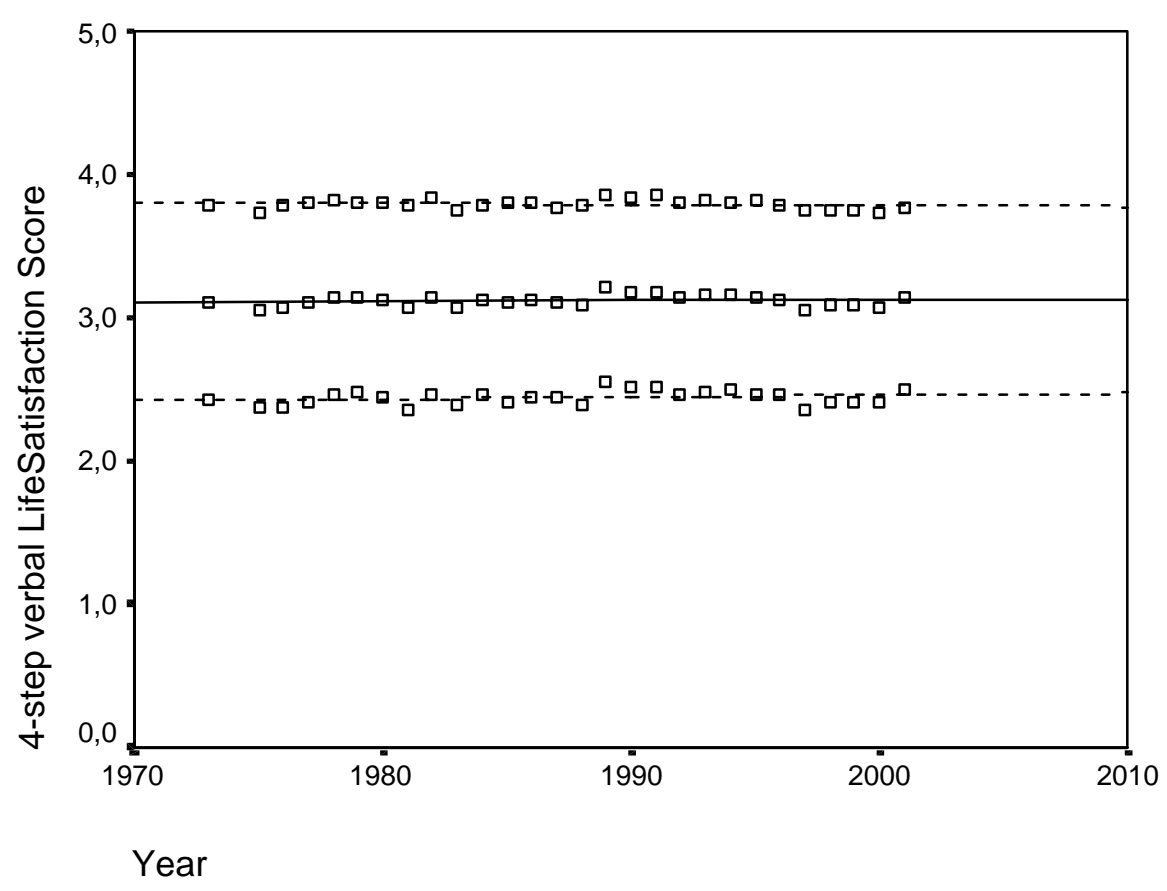

4 South-European Countries 1985-2001

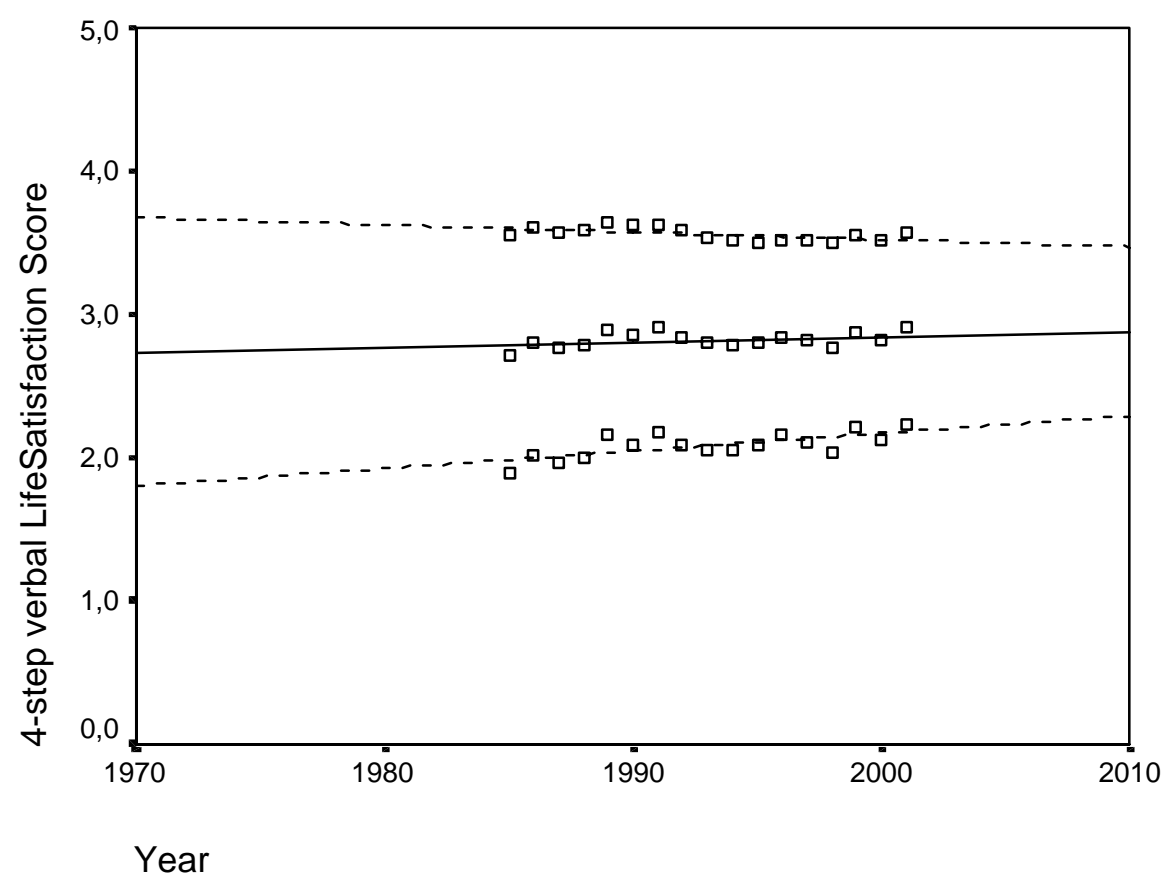




\section{Figure 7}

\section{Partial correlation analysis of level, dispersion and year.}

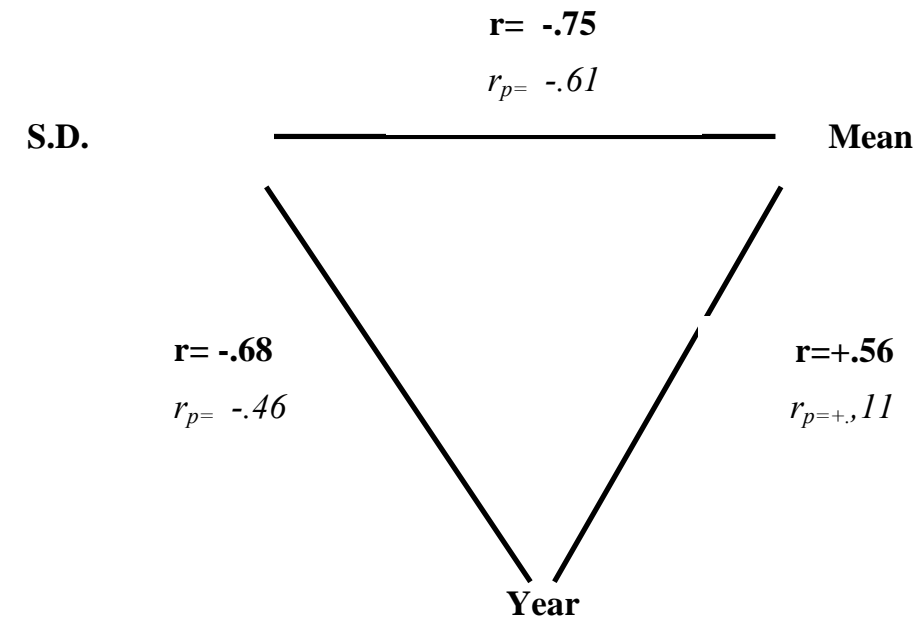

1973-2001, EU-members since 1973: Belgium, Denmark, France, West Germany, Ireland, Italy Luxembourg, Netherlands, and UK. Not included are nations that entered the EU later: East Germany, Greece, Portugal and Spain. 
Figure 8

Scattergram of SD life-satisfaction by economic development

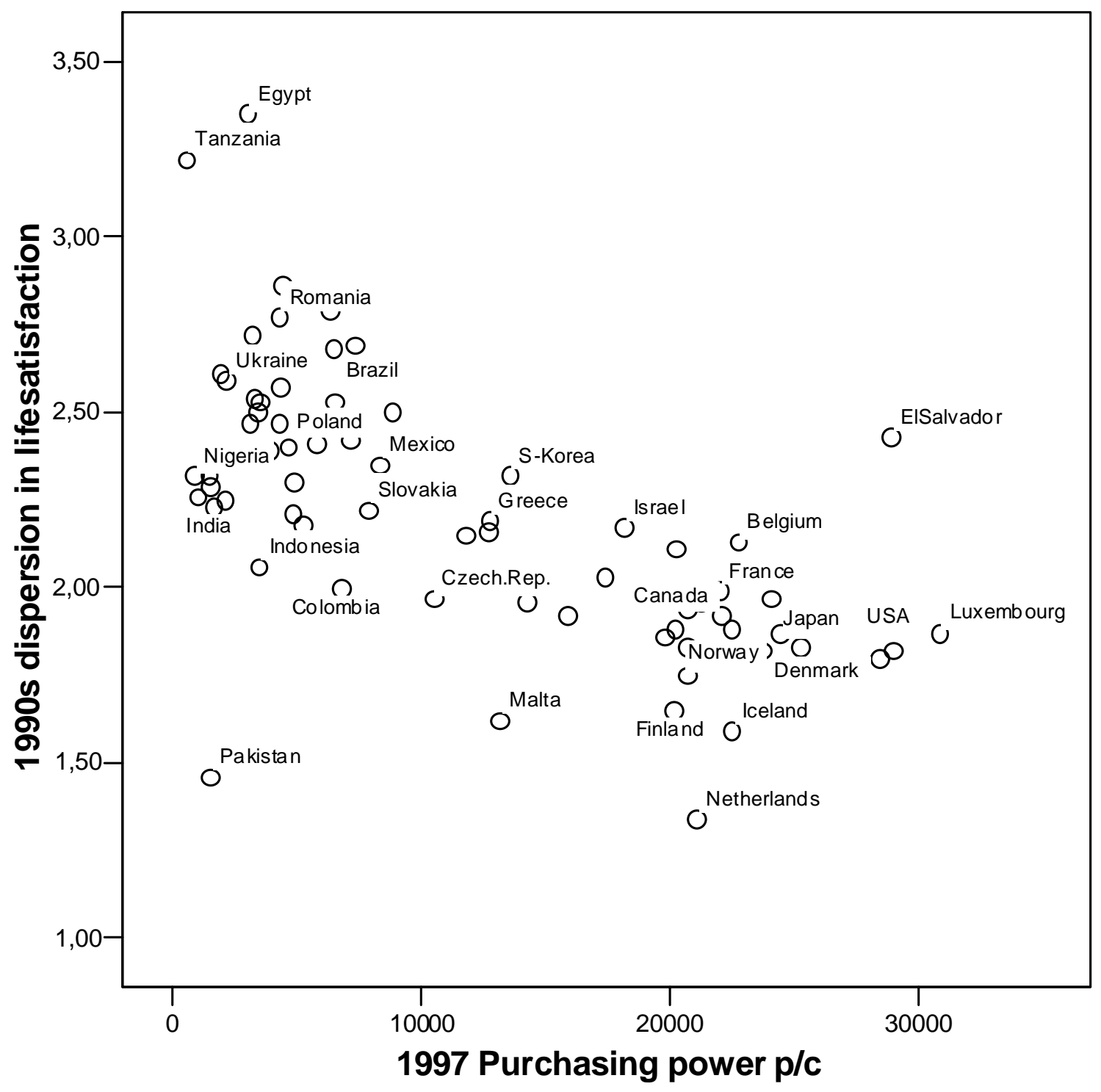




\section{REFERENCES}

Alderson, A.S. \& Nielsen, F. (2002)

Globalisation and the great U-turn: Income inequality trends in 16 OECD countries

American journal of Sociology, vol. 107, pp. 1244-1299

Bönke, P. (2001)

Nothing left to lose? Poverty and social exclusion in comparison

Paper FS III 01-402, WissenschaftsZentrum für Sozialforschung Berlin

Bulmahn, T. (2000)

Globalmasse des subjectiven Wohlbefindens

In: Statistisches Bundesambt (ed.) 'Datenreport 2000' Bundeszentrale für politische Bildung, Bonn, pp. 420-430

Diener, E. (1999)

Subjective wellbeing: Three decades of progress

Psychological Bulletin, 1999, Vol. 125, 276 - 301

Harrison, B. \& Bluestone, B. (1988)

The great $U$-turn

Basic Books, New York

Human Development Report (1998)

United Nations Development Program, Washington USA

Idler, E.L. \& Benyamini, Y (1997)

Self-rated health and mortality: a review of 27 community studies

Journal of Health and Social Behaviour, vol. 38, pp. 21-37

Iijima, K. (1982)

The feeling of satisfaction and happiness of the Japanese and other people

Working paper, Nippon Research Centre, Tokyo

Inglehart, R. (2004)

World Values Surveys and European Values Surveys 1999-2001. Data file, user guide and codebook

ICPRS file 3975, Inter-university Consortium for Political and Social Research, Ann Arbor, Michigan, USA

Kalmijn, W.M. \& Veenhoven R. (2005)

Measuring inequality of happiness in nations. In search for proper statistics

Journal of happiness studies, vol. 6 pp. ??-??

Kunst, A. (1997)

Cross-national comparisons of socio-economic differences in mortality

Dissertation, Erasmus University Rotterdam 
Kunst, A, Bos, V. \& Mackenbach, J (2001)

Recent trends in socio-economic inequalities in self assessed health in ten European countries Preliminary report, Erasmus University Rotterdam,

LeGrand, J. (1987)

Inequalities in health: Some international comparisons

European Economic Review, vol. 31, pp. 182-191

Marshall, G. (1997)

Repositioning social class. Social inequality in industrial societies

Sage, London

Michalos, A.C. (1985)

Multiple discrepancy theory

Social Indicator Research, vol. 16, pp. 347-413

Nolan, P.. \& Lenski, G. (2004)

Human societies. An introduction into macro sociology

Paradigm Publishers, Boulder, London

Noll, H-H. (1999)

New structures of inequality: Some trends of social change in modernising society

Paper FS III 99-405, WissenschaftsZentrum für Sozialforschung Berlin

Ott, J. (2005)

Level and inequality of happiness in nations, does greater happiness of a greater number imply greater inequality in happiness?

Journal of Happiness Studies, vol. 6, pp.?? -??

Pakulski, J. \& Waters, M. (1996)

The death of class

Sage, London, UK

Ritakallio, V-M. (2001)

Trends of poverty and income inequality in cross national comparison

Luxembourg Income Study Working Paper 272, INSTEAD, Differdange, Luxembourg

Ritzer, G. (2000)

The MacDonaldization of society

Pige Forge Press, USA

Sanderson, S.K. (1995)

Social transformations. A general theory of historical development

Blackwell, Oxford UK

Saris, W., \& Scherpenzeel, A.C. (1996)

Methodological procedures for comparative research

In: Saris, W.E., Veenhoven, R., Scherpenzeel, A.C. \& Bunting, B. (eds.), 'Comparative study of satisfaction with life in Europe', Eötvös University Press, Budapest, Hungary, pp.49-78 
Sassen, S. (1991)

The global city: New York, London, and Tokyo

Princeton University Press, Princeton USA

Stouffer, S.A. (1949)

The American soldier: combat and its aftermath

Princeton University Press, Princeton NJ, USA

VanPraag, B.M.S.(1989)

Income: Facts, perceptions and their interconnections

Oxford University Press, Oxford, UK

Veenhoven, R. (1990)

Inequality in happiness; Inequality in countries compared between countries

Paper presented at the $12^{\text {th }}$ World Congress of Sociology, Madrid, Spain

Veenhoven, R. (1991)

Is happiness relative?

Social Indicators Research, vol. 24, pp. 1-34

Veenhoven, R. (1993)

Happiness in nations: Subjective appreciation of life in 56 nations 1946-1992

RISBO, Erasmus University Rotterdam, Netherlands

Veenhoven, R. (1995)

The cross-national pattern of happiness: Test of predictions implied in three theories of happiness

Social Indicators Research vol. 34, pp. 33-68

Veenhoven, R. (1996)

Happy life expectancy: A comprehensive measure of quality-of-life in nations

Social Indicators Research, vol. 39, pp. 1-58

Veenhoven, R. (1997)

Progrés dans la compréhension du bonheur (Progress in the understanding of happiness)

Revue Québécoise de psychologie, vol. 18, pp. 29-74

Veenhoven, R. (1998)

Vergelijken van geluk in landen (Comparing happiness across nations)

Sociale Wetenschappen, vol. 42, pp. 58-84

Veenhoven, R. (1999)

Quality of life in individualistic society: A comparison of 43 nations in the early 1990s

Social Indicators Research, vol. 48, pp. 157-186

Veenhoven, R. (2000)

The four qualities of life: Ordering concepts and measures of the good life.

Journal of Happiness Studies, vol. 1, pp. 1-39 
Veenhoven, R. (2000b)

Well-being in the welfare state: Level not higher, distribution not more equitable

Journal of Comparative Policy Analysis, 2000, vol. 2, pp 91-125

Veenhoven, R. (2000c)

Freedom and happiness: A comparative study in 44 nations in the early 1990s

In: Diener, E. \& Suh, E.M. (Eds.) 'Culture and subjective well-being', MIT-Press, Cambridge Mass. USA, pp. 257-288

Veenhoven, R. (2003)

World Database of Happiness, Distributional findings in Nations, update 2003

www2.eur.nl/fsw/research/happiness

Veenhoven, R. (2004)

Equality of happiness in 90 nations 1990-2000: How much citizens differ in enjoyment of their life-as-a-whole

World Database of Happiness, Distributional findings in nations, Rank Report 2004/3b.

Available at: http://www.worlddatabaseofhappiness.eur.nl

Veenhoven, R. (2005)

Trends in equality of happiness in nations 1946-2004

World Database of Happiness, Distributional Findings in nations, Trend Report 2005-3c

Available at: http://www.worlddatabaseofhappiness.eur.nl

Veenhoven, R. (2005b)

Is life getting better? How long and happy people live in modern society

Paper under review

Veenhoven, R. \& Timmermans, D. (1998)

Welvaart en geluk

Economisch Statistische Berichten (ESB), vol. 83, pp. 628-631

Wilterdink, N. (1993)

Ongelijkheid en interdependentie: ontwikkelingen in welstandsverhoudingen

Oratie Utrecht University, Wolters Noordhof, Groningen

World Culture Report 1998

UNESCO, Paris, France 


\section{NOTES}

${ }^{1}$ An earlier version of this paper was published in German in Glatzer, W., Habich, R. \& Mayer, K-U. (Eds.) Sozialer Wandel und gesellschaftliche Dauerbeobachtung, Festschrift für Wolfgang Zapf, Leske + Budrich, Opladen, Germany, 2002, pp. 273-294

${ }^{2}$ The initial rise in income inequality after the industrial revulution is known as the kunetz curve (Kunetz 1955)

${ }^{3}$ One of the problems is assessing how much people earn, especially if non-monetary income is involved. Another problem is adjusting for household size, so called 'equivalence income'.

${ }^{4}$ The correlation between household income and life-satisfaction reflects not only causal effects of income on life-satisfaction, but also effects of life-satisfaction on earning chances. Moreover, part of the correlation is due to a spurious effect of health.

${ }^{5}$ This pattern is reproduced in the dataset used here (which involves 10 more nations). The correlation between income-inequality in nations and average life-satisfaction is +.04 , the correlation with self-rated health is +.12 . This lack of correlation is not due to insensitivity of life-satisfaction or self-rated health, since these variables appear to be strongly related to nation characteristics such as economic development, political freedom and good governance.

${ }^{6}$ This might seem incompatible with the common finding that, with-in nations, relatively poor people tend to be less healthy, though hardly less happy. Yet this correlation is not necessarily caused by low-income position and can also be due to selection (less earning power of the less healthy) and culture (health behavior of the poor). The absence of a correlation at the nation level adds to the plausibility of these alternative explanations for the correlation at the individual level.

${ }^{7}$ Using self-rated health instead could solve both problems. This appears to be a good predictor of longevity (Idler \& Benyamini 1997) and timely measurement is possible by surveys. Self-rated health is an item in the World Value Surveys, so comparison across nations is possible. Comparison across time is less easy; though several nations have time series of twenty years or more, the items are not identical.

${ }^{8}$ About $80 \%$ of the differences in average life-satisfaction in nations can be explained by variation in ,hard societal characteristics such as affluence, freedom and justice (Veenhoven 1997)

${ }^{9}$ If involved at all, this distortion is must be limited. Later on we will see that $77 \%$ of the differences in dispersion of life-satisfaction can be explained by country characteristics such as economic affluence and respect for human rights, which is unlikely to occur if standard deviations of life-satisfaction were much attenuated by random measurement error.

10 The word 'happiness' is used synonymously with 'life-satisfaction'

11 'Negatively skewed' means that the skew is at the negative side of the distribution and this implies more observations at the positive side.

12 Life-satisfaction was assessed only once in the years 1997, 1998 and 1999.

${ }^{13}$ This test of significance is based on the assumption that these observations represent an a-select sample of time points in that era. This assumption is not too far fetched, since we are dealing with data from periodical surveys. In the comparison accross nations in section 3.3, I will not subject the observed correlations to a significance test, because the set of nations considered cannot be considered to be a sample from a wider population.

${ }^{14}$ The 10-step life-satisfaction item is less vulnerable to this type of distortion, but the World Value Studies do not (yet) allow comparison over a substantial period of time.

${ }^{15}$ Economic development measured by buying power p/c. Data Human Development Report 1998. 
${ }^{16}$ Freedom in private life measured by opportunity to choose in matters of marriage, procreation, religion and termination of ones own life. Opportunity to choose measured by public acceptance and absence of legal restraint. Data drawn from Veenhoven (2000c)

${ }^{17}$ Informatization measured by internet users p/c. Data Human Development Report 1998

${ }^{18}$ Urbanization measured by \% urban population. Data Human Development Report 1998

${ }^{19}$ Educational level in nations measured by gross school enrolment ratio. Data Human Development Report 1998

${ }^{20}$ Income-inequality in nations in the 1990 s as measured by the Gini-coefficient of the total income distribution. Data: World Culture Report table 28. 